\title{
RECUBRIMIENTO COMESTIBLE CON BASE DE PIÑON MEXICANO (Jatropha curcas), SOBRE LA CALIDAD DE CHAYOTE MINIMAMENTE PROCESADO
}

\section{EFFECT OF EDIBLE COATING MADE WITH MEXICAN PINE NUT (Jatropha curcas) ON THE QUALITY OF MINIMALLY PROCESSED CHAYOTE}

\author{
Espinoza-Tirzo, M. ${ }^{1}$; Ríos-Cortés, A.M. ${ }^{2}$; Martínez-Ayala, A.L. ${ }^{3}$; Ramírez-Romualdo, J.V. ${ }^{1}$; García-Osorio, C. ${ }^{4}$; Arévalo-Galarza, M.L. ${ }^{*}$ \\ ${ }^{1}$ Universidad Interserrana del Estado de Puebla-Ahuacatlán. Los Llanos Km. 1 Carretera Amixtlán \\ San Andrés Tlayehualancingo. Ahuacatlán, Puebla. ${ }^{2}$ Instituto Politécnico Nacional - CIBA, Carrete- \\ ra Estatal Santa Inés Tecuexcomac-Tepetiltla Km. 1.5, Tepetitla de Lardizábal, Tlaxcala. ${ }^{3}$ Centro de \\ Desarrollo de Productos Bióticos Carretera Yautepec-Jojutla km 6. CEPROBI No. 8 Colonia San \\ Isidro, Yautepec, Morelos, México. ${ }^{4}$ Colegio de Postgraduados, Campus Montecillo, Posgrado de \\ Fruticultura, Km. 36.5 Carretera. México-Texcoco. Montecillo, Edo. de México.
}

*Autor de correspondencia: larevalo@colpos.mx

\begin{abstract}
Mexico is the world's number one producer and exporter of chayote (Sechium edule (Jacq.) Sw.), with more than $90 \%$ of its exports based on the cultivated smooth green variety (var. virens levis), whose commercialization is primarily as fresh fruit. Therefore, it is important to develop new products and take advantage of the global trend in consumption of minimally processed fresh products, market that shows surprising annual increments. In this study we show the results from the quality assessment of precut and packed chayote fruits, stored for 15 days at $5{ }^{\circ} \mathrm{C}$, subjected to different treatments. The results showed that application of the edible chitosan and protein based covering derived from Jatropha curcas, and citric acid $(1 \%)$, preserves the characteristics of fruit quality to a higher degree, primarily appearance and flavor. However, the fruits only conserved their optimal quality for up to 12 days of storage under refrigeration, which is why it is important to test more treatments in order to find ideal coverings for the conservation of chayote fruit.
\end{abstract}

Keywords: chitosan, Jatropha curcas, shelf life, refrigeration.

\section{RESUMEN}

México es el primer productor y exportador mundial de chayote (Sechium edule (Jacq.) Sw.), basando más del 90\% de sus exportaciones en la variedad cultivada verde liso (var. virens levis), cuya comercialización es principalmente como fruto fresco. Por lo que es importante desarrollar nuevos productos y aprovechar la tendencia mundial del consumo de productos frescos mínimamente procesados, mercado que muestra incrementos anuales sorprendentes. En este trabajo se muestran los resultados de la evaluación de la calidad de frutos de chayote precortado y empacado, almacenado por 15 días a $5{ }^{\circ} \mathrm{C}$, sometido a diferentes tratamientos. Los resultados mostraron que la aplicación del recubrimiento comestible a base de quitosano y proteína derivada de Jatropha curcas, y ácido cítrico (1\%) preserva en mayor grado las características de calidad de los frutos, principalmente en apariencia y sabor. Sin embargo, los frutos solamente conservaron su calidad óptima hasta 12 días de almacenamiento bajo refrigeración, por lo que es importante, probar mayor número de tratamientos a fin de encontrar recubrimientos ideales para la conservación del fruto de chayote.

Palabras clave: quitosano, Jatropha curcas, vida de anaquel, refrigeración.

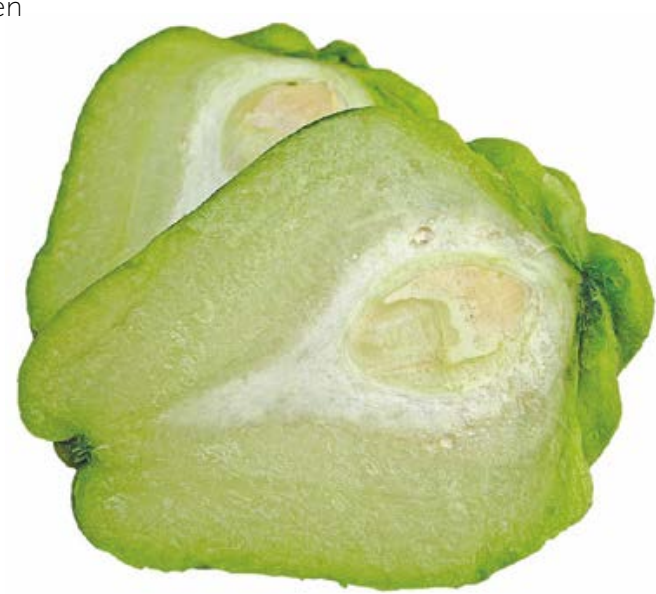




\section{INTRODUCCIÓN}

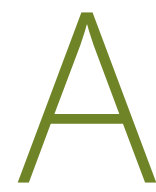

ctualmente, el consumidor demanda alimentos de alta calidad y valor nutricional. La recomendación para una dieta balanceada incluye el consumo de frutas y hortalizas; sin embargo, debido a las exigencias laborales y las restricciones de tiempo, ha surgido el mercado de los productos de consumo inmediato. En este sentido los productos precortados, mínimamente procesados o IV gama responden a la tendencia de satisfacer la necesidad de mercados como el de las grandes ciudades, donde los consumidores disponen de menos tiempo para la preparación de sus alimentos (Artés y Allende 2005). Estos productos están libres de aditivos y requieren

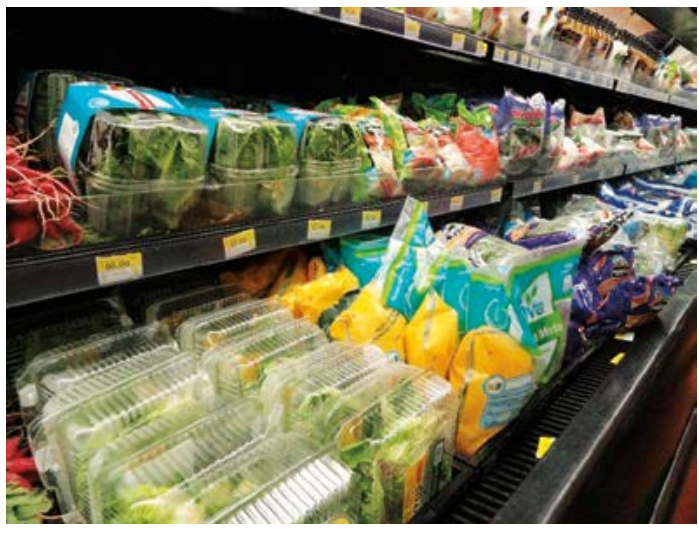

Figura 1. Productos precortados o mínimamente procesados en tiendas de autoservicio. con productos que retrasen su deterioro. Tal es el caso de los recubrimientos comestibles, que reducen la migración de humedad, restringen el oxígeno disponible y evitan el oscurecimiento enzimático, incluso reducen los desórdenes fisiológicos, prolongando la vida de anaquel de los productos (Ramos-García et al., 2010). un mínimo o ningún procesa-

miento antes de su consumo. Debido a estas características, la demanda de estos productos ha crecido exponencialmente en los últimos años, por ejemplo, en Estados Unidos es el segmento de mayor crecimiento en su categoría, con un estimado de \$27 US billones con un aumento del 4 \% para el año 2012 con relación al año anterior (UFPA, 2016) (Figura 1).

Después de la cosecha las frutas y hortalizas aceleran su deterioro, más aún si son procesadas para el consumo como productos precortados, ya que son más sensibles a los desórdenes que los frescos. Este deterioro se debe principalmente a que el tejido vegetal es cortado, e incrementa el metabolismo, actividad enzimática, pérdida de líquido celular, pérdida de firmeza y color, así como mayor susceptibilidad a la invasión de microorganismos, entre otros (Figura 2).

Por lo anterior, es una práctica común que a los productos mínimamente procesados se les trate

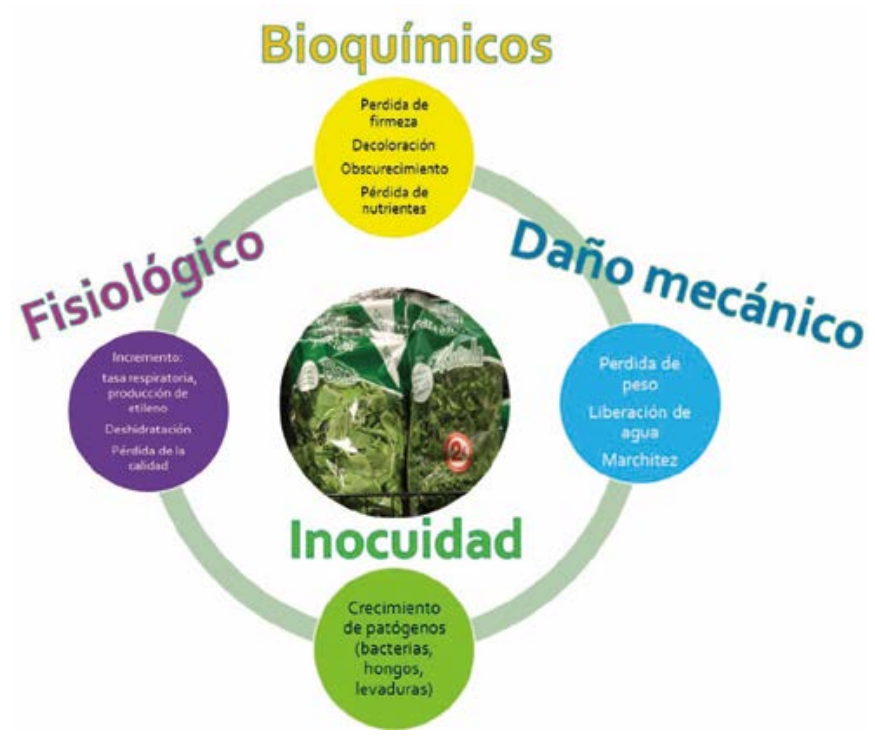

Figura 2. Factores que afectan los productos precortados o mínimamente procesados que reducen su vida de almacenamiento (Modificado de Artés y Allende 2005).
El quitosano es un polímero derivado de quitina, sus propiedades fisicoquímicas y biológicas lo han hecho un ingrediente común en la formulación de recubrimientos comestibles, ya que posee actividad antimicrobiana, es emulsificante y antioxidante y actúa como una fibra soluble. El quitosano se obtiene de los caparazones de los crustáceos o puede ser producidos por algunos hongos. En comparación con los otros materiales, el quitosano tiene la ventaja de ser capaz de incorporar sustancias con actividad funcional (Falguera et al., 2011). El piñón mexicano (Jatropha curcas), una planta es originaria de Mesoamérica, que se encuentra en varios estados de México (Sinaloa, Oaxaca, Quintana Roo, Veracruz, Yucatán, Morelos, Sonora, Tamaulipas, Chiapas, Hidalgo, Puebla, Guerrero y Tabasco); sin embargo, solo se utiliza en la cocina tradicional. El fruto de Jatropha curcas es una cápsula con tres semillas elipsoides blancas, con testa obscura, de $2 \mathrm{~cm}$ de largo y peso promedio de $0.65 \mathrm{~g}$. Su contenido de aceite es del 58-60 \% y proteína 27-32 \%, además de que posee propiedades medicinales. El principal uso que se le da a la planta es para producir aceite. El residuo que permanece después de su extracción, es una buena fuente de proteína, dentro de esta se encuentra la curcina o curcín que es una toxoalbúmina, que después de someterse a un tratamiento térmico pierde su efecto tóxico (Galaz-Ávalos et al., 2012; Adebowale y Adedire, 2006). 
En algunos lugares estas semillas no son comestibles ya que son consideradas toxicas debido a la presencia de saponinas, lectinas, fitatos, inhibidores de tripsina, pero el principal tóxico es el éster de forbol, el cual le confiere el efecto purgante a la semilla. En algunas variedades de J. curcas presentes en México, los esteres de forbol están casi ausentes, lo cual ofrece la posibilidad de incluir en productos destinados al consu-

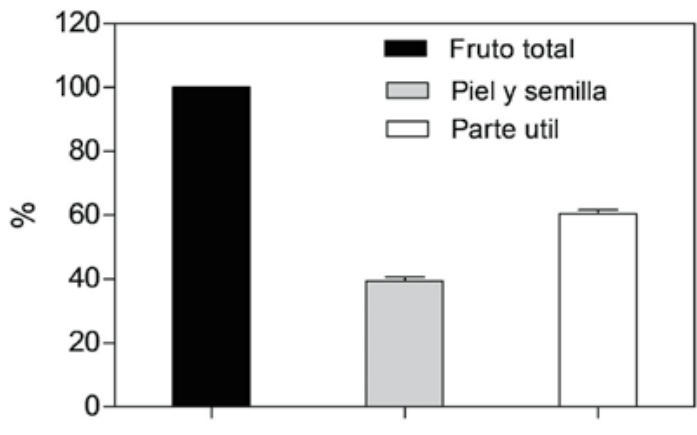

\section{Composición del fruto}

Figura 3. Porcentaje de aprovechamiento de la parte útil del fruto de chayote var. virens levis para su utilización como fruto precortado.

150 ppm por 1 min, trascurrido el tiempo se dejaron secar por 5 min para eliminar el exceso de solución.

\section{Recubrimiento comestible}

Para la elaboración de la solución de quitosano al $1.5 \%$, se utilizaron $30.05 \mathrm{~g}$ de quitosano (Sigma Aldrich ${ }^{\text {TM}}$ ) en 2.070 L de agua destilada a la que se añadió $20.7 \mathrm{~mL}$ de ácido acético glacial $(99.85 \%$, Sigma Aldrich ${ }^{\mathrm{TM}}$ ) al $1 \%$, dejándolo en mo humano y animal. En este sentido la inclusión de proteína subproducto de la extracción de aceite del piñón mexicano en la solución de quitosano muestra una opción para mejorar las características del recubrimiento comestible (Ortíz-Calderón, 2012; Makkar et al., 1998). Por lo anterior y con el objetivo de diversificar la oferta de chayote de exportación hacia producto mínimamente procesado, en este trabajo se evalúo el comportamiento de frutos de chayote $S$. edule var. virens levis con el uso de un recubrimiento comestible a base de quitosano y proteínas derivadas de piñón mexicano (Jatropha curcas L.).

\section{MATERIALES Y MÉTODOS Material vegetal}

Se utilizaron frutos de chayote ( $S$. edule var. virens (evis), cosechados en enero de 2016 procedentes de una huerta comercial del municipio de Huatusco, Veracruz, México. Los frutos fueron trasladados al laboratorio y se seleccionaron con base a su uniformidad, tamaño, color, forma y ausencia de daños y la infección por hongos. Los frutos seleccionados se lavaron con una solución clorada (150 ppm), y posteriormente se les eliminó el pericarpio y se cortaron en cubos de $3 \times 1 \mathrm{~cm}$. El rendimiento del fruto para el aprovechamiento de la parte útil fue del 60 \% (Figura 3).

Los trozos de chayote se sumergieron en una solución clorada de

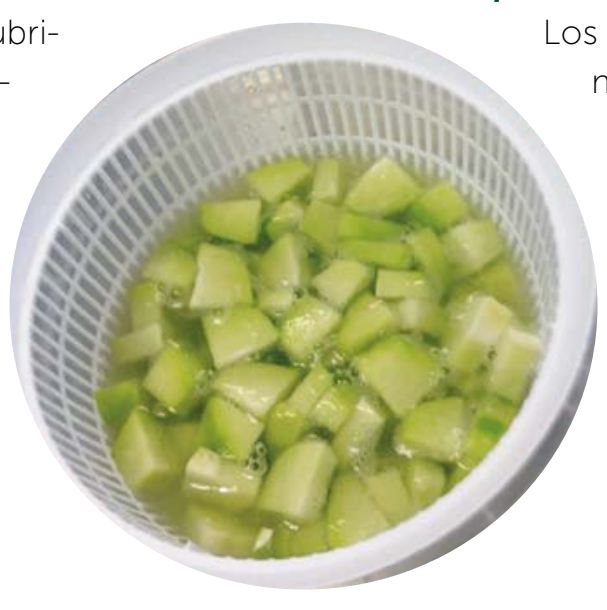

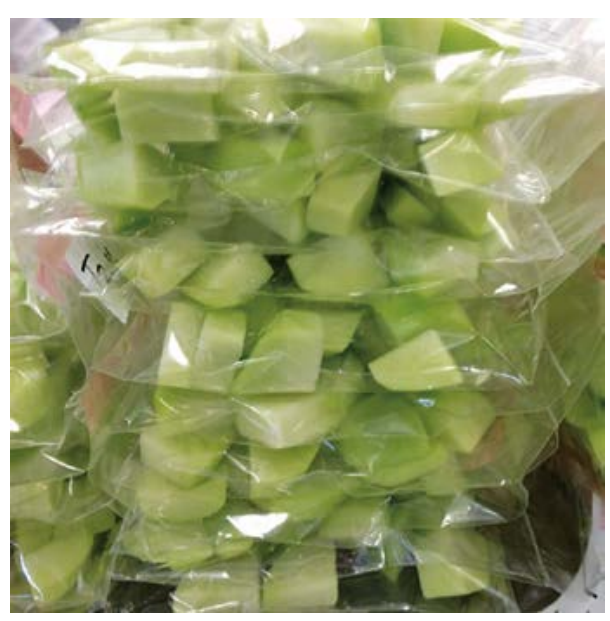

Figura 4. Inmersión en recubrimiento comestible y empaque con fruto. agitación durante $48 \mathrm{~h}$ y adicionando $230 \mathrm{~mL}$ de glicerol (5\%) (J. T. Baker TM) como plastificante. Posteriormente se agregó la fracción glutelína de la semilla de Jatropha curcas $(0.6 \%)$ a la solución de quitosano, en una proporción 60:40 respectivamente y glicerol al 5\% como plastificante y se agitó nuevamente hasta su aplicación (Figura 4)

\section{Aplicación de Tratamientos}

Los frutos de chayote se sometieron a inmersión por 2 min en cada solución que representó un tratamiento: 1) Testigo (agua destilada); 2) Ácido cítrico (1\%) (AC) 3) Recubrimiento Comestible (RC); 4) Recubrimiento Comestible+ácido cítrico (1\%) $(R C+A C)$. Posteriormente a los trozos de chayotes de cada tratamiento se les eliminó el exceso de humedad. Finalmente, por cada tratamiento se empacaron 12 bolsas de celofán (espesor: $25 \mu \mathrm{m}$ y permeabilidad vapor de agua $1.34 \times 10^{-11} \mathrm{~g} \mathrm{~m}^{-1} \mathrm{~s}^{-1} \mathrm{~Pa}^{-1}$ ) considerando una repetición por bolsa, con un peso aproximado de 190210 g cada una. Una vez envasados se almacenaron a $5{ }^{\circ} \mathrm{C}$. Los análisis se realizaron a los $0,4,8$, 12 y 15 días de almacenamiento. Las variables evaluadas fueron:

\section{Pérdida de Peso}

El peso de cada bolsa se registró con una balanza analítica Voyager ${ }^{\circledR}$ Pro (Mod. VP114CN, Ohaus, 
Suiza). Los resultados fueron expresados como porcentaje de la pérdida de peso con respecto al peso inicial, utilizando la siguiente ecuación:

$$
\% \text { Pérdida de Peso }=\frac{\text { peso inicial }- \text { peso final }}{\text { peso inicial }} \times 100
$$

\section{Sólidos Solubles Totales}

Se determinó usando un refractómetro digital Atago (PAL-1. ${ }^{\circ}$ Brix: $0-53^{\circ}$ )

\section{Contenido de Azúcares}

Se realizó al principio y al final del periodo de evaluación, por el método modificado de Mustafa et al. (2003). Para la elaboración de los extractos se pesaron $5 \mathrm{~g}$ de fruto de chayote triturado y se le agregaron $60 \mathrm{~mL}$ de etanol al $80 \%$ en un matraz de $250 \mathrm{~mL}$ con tres perlas de ebullición. Se calentó en una parrilla de agitación magnética (Thermo Cientific TM) hasta reducir su volumen a $10 \mathrm{~mL}$. Se filtró con algodón y se refrigeró por $24 \mathrm{~h}$. Los extractos se filtraron por cartucho de limpieza (Cromabond $^{\circledR} \mathrm{C}_{18} 45 \mu \mathrm{m}$, MachereyNagel). Pasando primero $6 \mathrm{~mL}$ de metanol grado HPLC, $6 \mathrm{~mL}$ de agua grado HPLC, $1 \mathrm{~mL}$ de extracto y finalmente $3 \mathrm{~mL}$ de agua grado HPLC dejándolos en un matraz erlemeyer y posteriormente aforarlos a $5 \mathrm{~mL}$ con agua grado HPLC. Se tomó $1 \mathrm{~mL}$ de la solución aforada el cual se filtró con un acrodisco (Titan, $0.045 \mu \mathrm{m}$ ) y se colocó en un vial de $2 \mathrm{~mL}$ con tapa y septa. Se colocaron los extractos filtrados en el automuestrador del HPLC (High-Performance Liquid

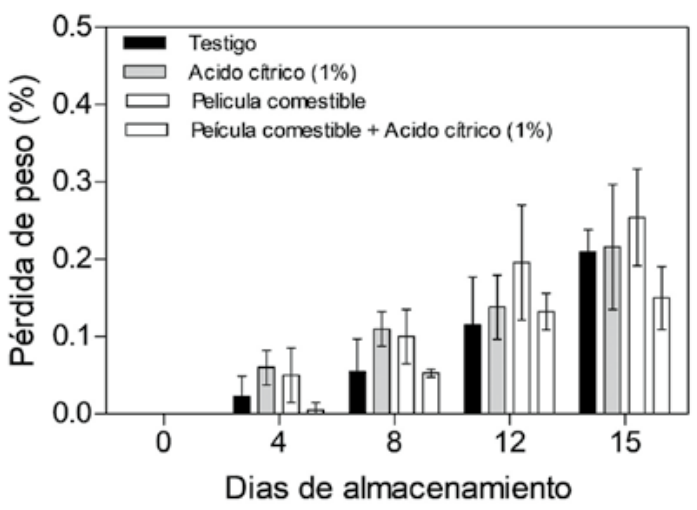

Figura 5. Pérdidas de peso de los diferentes tratamientos de chayote ( $S$. edule var. virens levis) empacados en película de celofán y almacenados a $5^{\circ} \mathrm{C}$ por 15 días $(n=12 \pm D E)$ aroma, sabor y textura. Los atributos se evaluación con una escala de 1-9. La prueba de aceptación se realizó a intervalos de 5 d tomando 3 repeticiones de cada tratamiento.

\section{Cuenta microbiana (Aerobios totales)}

Para el análisis microbiológico se realizó en medios de cultivo de $\mathrm{NeoFilm}^{\circledR}$ (3M) para el recuento de aerobios totales, para ello se tomaron muestras al azar de cada tratamiento y mezcló con agua destilada, de allí se tomó $1 \mathrm{~mL}$ y se colocó en el medio de cultivo, para incubarse a $35^{\circ} \mathrm{C}$ por $48 \mathrm{~h}$.

\section{RESULTADOS Y DISCUSIÓN \\ Pérdida de Peso}

Una de las causas más importantes del deterioro es la pérdida de peso durante el almacenamiento pues influye en la textura y calidad del producto, lo que determinará el criterio de consumo. En este sentido, todos los tratamientos presentaron una pérdida mínima durante el almacenamiento, con valores menores al $0.3 \%$ (Figura

5). Sin embargo, es importante resaltar que después del día 10 de almacenamiento, y como consecuencia de la pérdida de firmeza y ablandamiento del tejido se presentó la pérdida de fluido celular, lo cual provocó deterioro del producto. Brown et al. (2009) probaron diferentes empaques plásticos en lechuga (Lactuca sativa L.) precortada, observando pérdidas de peso de $0.25 \mathrm{~g}$ en $14 \mathrm{~d}$ de almacenamiento siendo menor el marchitamiento en la película plástica de doble capa laminada de polietileno y polipropileno orientado (PE/OPP).

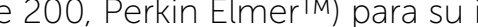
yección. Las condiciones del cromatógrafo fueron: temperatura del horno de $40{ }^{\circ} \mathrm{C}$, flujo de $1 \mathrm{~mL}^{-1}$, volumen de inyección de $10 \mu \mathrm{L}$ y detector de índice de refracción (Perkin Elmer Series 200). La fase móvil fue una solución de acetonitrilo:agua (80:20) y se empleó una columna Pinnacle II Animo $5 \mu \mathrm{m}$ 150x4.6 mm (Restek ${ }^{\mathrm{TM}}$ ), con un tiempo de corrida de 8.2 min.

\section{Prueba de Aceptación}

Esta prueba fue realizada mediante un método descriptivo de puntajes con un panel conformado por $10 \mathrm{ca}$ tadores. Se evaluaron los atributos de apariencia, color

\section{Sólidos Solubles Totales y Azúcares}

El contenido de sólidos solubles totales tuvo pequeñas variaciones ( 4.5 a $5.7^{\circ} \mathrm{Brix}$ ) entre el día 5 y 15. Con relación al contenido de azúcares, se observó que de forma general la proporción de glucosa y fructosa fue similar. con un contenido muy bajo de sacarosa $(<1 \%)$, o casi inexistente en las muestras iniciales y en el tratamiento 4: RC+AC. Es importante destacar que los tratamientos que conservaron después de 15 días de almacenamiento el mayor grado de dulce, fueron frutos con AC (1\%) (Figura 6). 


\section{Prueba de Aceptación}

El color es uno de los atributos que condiciona la compra de frutas y hortalizas, y como se observa en la Figura 7, el color característico del fruto de virens levis al inicio del experimento fue de un verde claro, que cambia a tonos amarillo-café; mientras que el color de los frutos del tratamiento $\mathrm{PC}+\mathrm{AC}(1 \%)$ fue evidentemente más claro, quizás debido a la pérdida de clorofila, pero sin presentar signos de oxidación. El ácido cítrico es conocido por su poder quelatante efectivo en la actividad de polifenol oxidasa. El pelado y cortado del fruto, dañan las células y promueven condiciones para que los sustratos y enzimas se pongan en contacto, provocando el oscurecimiento (Artés y Allende, 2005). Los productos mínimamente procesados entonces envejecen, provocando cambios a nivel bioquímico y fisiológico con la consecuente actividad microbiológica y degradación de firmeza y color.

Las enzimas de mayor importancia en estos productos son la polifenol oxidasas y la lipoxidasa causantes del obscurecimiento y mal olor (producción de aldehídos y cetonas). Además, con el precortado, la actividad respiratoria del producto se incrementa entre 20 y $700 \%$ o más, dependiendo de su metabolismo y temperatura de conservación, por lo cual es fundamental mantener estos productos en refrigeración. Si el producto esta envasado en una atmósfera muy baja en oxígeno, se provocara la anaerobiosis con la consecuente formación de etanol, cetonas y aldehídos (Francis et al., 2012).
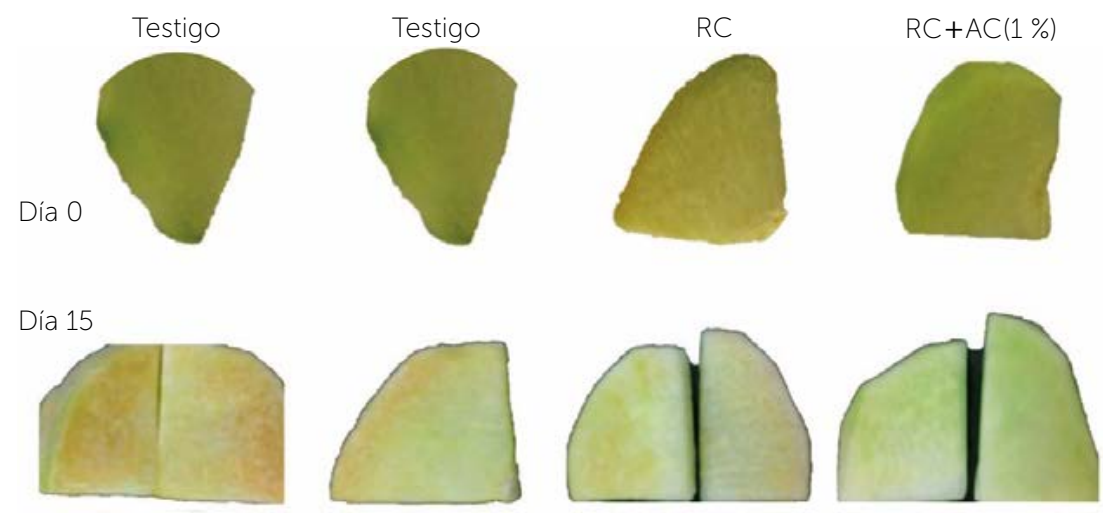

Figura 7. Cambios de color de chayote S. edule var. virens levis. Testigo; Ácido Cítrico (AC $1 \%$ ); Recubrimiento Comestible (PC); Recubrimiento Comestible+Ácido Cítrico $(P C+A C(1 \%)$. de $12 \mathrm{~d}$, ya que a los 15 d empezó a desprender aromas desagradables, sabores indeseables y el rechazo de los consumidores. En general el tratamiento RC+AC tuvo las mejores calificaciones, mientras que el tratamiento testigo tuvo la menor calificación en el color, debido a los problemas de oxidación.

\section{Cuenta Total de Aerobios}

Durante el pelado, cortado y triturado de los frutos, las superficies del producto son más expuestas al crecimiento de bacterias, levaduras y hongos. En productos mínimamente procesados, tienen en general una baja acidez ( $\mathrm{pH}$ 5.8-6.0), alta humedad y gran superficie de corte que provee un medio ideal para el crecimiento de estos microorganismos. La población de las bacterias en frutas y vegetales es muy amplia, y la microflora predominante en hojas frescas son Pseudomonas y Erwinia spp., con cuentas iniciales de solo $105 \mathrm{cfu} \mathrm{g}^{-1}$, con poca cantidad de hongos y levaduras. Durante el almacenamiento en frio se han registrado cepas de Pseudomonas sp. pectinoliticas que son responsables de la pudrición blanda (García-Gimeno y Zurera-Cosano, 1997).

Un incremento en la temperatura de almacenamiento y concentración de dióxido de carbono en el empaque puede incrementar la población de bacterias acidas. Además, es importante considerar que bacterias, tales como Listeria monocytogenes, Pseudomonas spp. o Micrococcus spp. son psicrotróficas, pues cuentan con proteínas y lípidos de la membrana que soportan las bajas temperaturas, pudiendo desarrollar a dichas temperaturas (Artés y Allende, 2005). En la Figura 9, se observa 


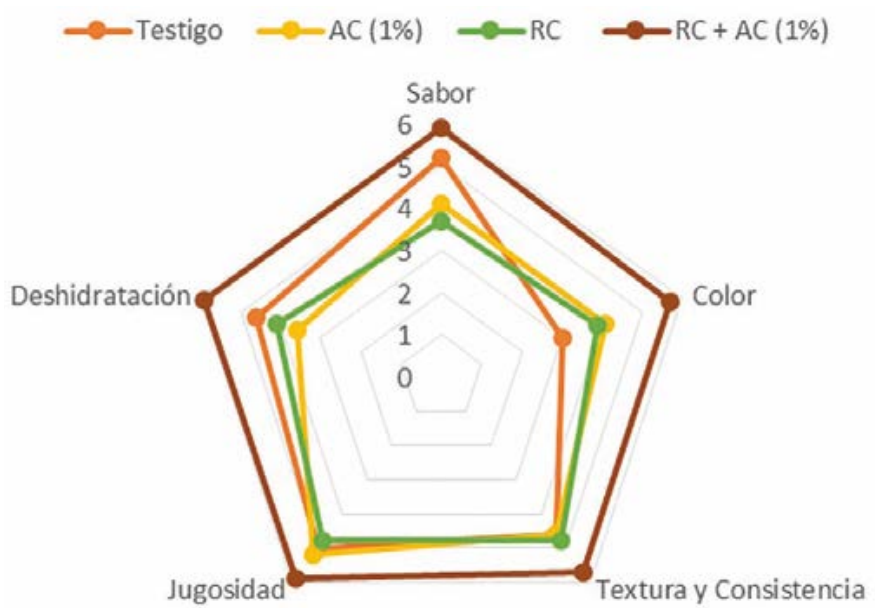

Figura 8. Atributos de calidad en frutos de chayote mínimamente procesado (S. edule var. virens levis) analizados a los 15 días de almacenamiento a una temperatura de $5^{\circ} \mathrm{C}$.

en general que todos los tratamientos tuvieron menor crecimiento microbiano a los 10 d en comparación con el testigo, principalmente aquellos con AC (1\%) siendo más efectivo en el tratamiento RC+AC (1\%). Sin embargo, es necesario realizar más trabajos enfocados a probar otros compuestos a fin de reducir en mayor grado el crecimiento microbiano e incrementar la vida de anaquel de los frutos de chayotes precortados.

\section{CONCLUSIONES}

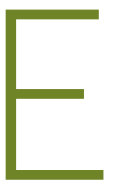

I desarrollo de productos como el chayote mínimamente procesados ofrece una excelente opción para el mercado debido a que presenta características organolépticas y una vida de anaquel aceptable. El uso de recubrimientos comestibles a base de quitosano y proteína derivada de Jatropha curcas probó preservar las características de calidad y reducir la incidencia de microorganismos comparada con el tratamiento testigo, sin embargo, la preparación del recubrimiento enfrenta algunos inconvenientes para su aplicación en la industria. Por lo anterior es necesario realizar mayor investigación para encontrar un tratamiento que prolongue más aún la vida de anaquel de los productos a bajo costo y con mayor facilidad de preparación.

\section{AGRADECIMIENTOS}

Los autores agradecen el apoyo recibido para la elaboración de este proyecto al Instituto Politécnico Nacional (IPN).

\section{LITERATURA CITADA}

Adebowale K.O., Adedire C.O. 2006. Chemical composition and insecticidal properties of the underutilized Jatropha curcas seed oil. Afr. J. Biotechnol. 5: 901-906.

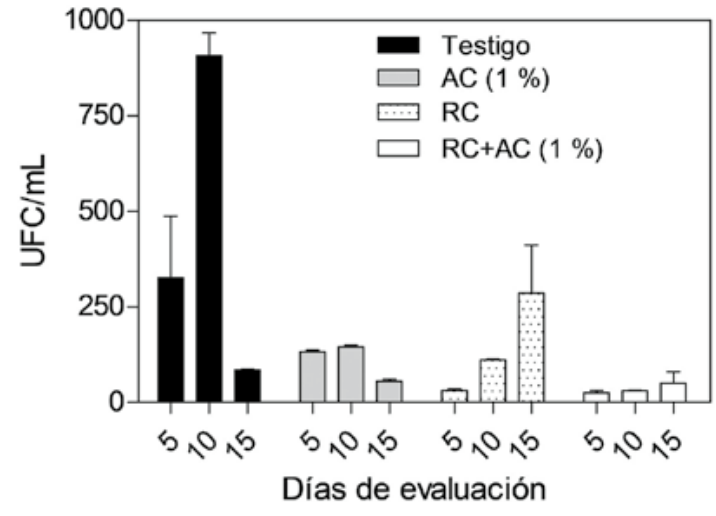

Figura 9. Cuenta total de mesófilos aerobios presentes en frutos de chayote mínimamente procesado almacenados a $5{ }^{\circ} \mathrm{C}$ por diferentes periodos de tiempo. $(n=3 \pm D E)$

Artés F., Allende A. 2005. Minimal fresch processing of vegetables, fruits, and juices. In Emerging technologies for food processing. Chapter 26:677-716. ISBN: 0-12-676757-2. Elsevier Ltd.

Brown J., Vorst K., Palmer S., Singh J. 2009. Performance of pre-cut lettuce packaged in biodegradable film formed on commercial vertical-form-fill-and-seal machines. J. Applied Packaging Research. 3(1): 1- 14.

Falguera V., Quintero J., Jiménez A., Muñoz A., Ilbarz A. 2011. Edible Films and Coatings: Structures, active functions and trends in their use. Trends in Food Science and Technology. 22: 292303.

Francis G.A., Gallone A., Nychas,G.J., Sofos J.N., Coleli G., Amodio M.L., Spano G. Factors affecting quality and safety of fresh cut produce. Critical Reviews in Food Science and Nutrition. 52 595-610

Galaz-Ávalos R.M., Avilez-Montalvo R.N., Ucan-Uc C.M., Chan-López J.A., Loyola-Vargas V.M. 2012. Jatropha curcas una alternativa para la obtención de biodiésel sin afectar al sector alimentario. BioTecnología 16(2):94-114

García-Gimeno R.M., Zurera-Cosano G. 1997. Determination of ready to eat vegetable salad shelf life. International Journal of Food Microbiology 36 (1): 31-38

Makkar H.P.S., Becker K., Schmook B. 1998. Edible provenances of Jatropha curcas from Quintana Roo state of Mexico and effect of roasting on antinutrient and toxic factors in seeds. Plant Food for Human Nutrition. 52:31-36.

Ortíz-Calderon A.L. 2012. Composición química de jatrofa (Jatropha curcas) tóxica, no tóxica y detoxificada, y efecto de su consumo sobre parámetros nutricionales y tóxicos en pollos. Tesis Maestria. Universidad Autónoma de Queretaro. Facultad de Química. 84 p.

Ramos-García M.L., Bautista-Baños S., Barrera-Necha L.L., BosquezMolina E. 2010. Compuestos Antimicrobianos Adicionados en Recubrimientos Comestibles para Uso en Productos Hortofrutícolas. Revista Mexicana de Fitopatología. 28(1): 4457.

UFPA. 2016. Facts. United Fresh Produce Association. http://www unitedfresh.org/ (Consultado el 19 de septiembre del 2016). 